\title{
El Convenio sobre los aspectos civiles de la sustracción internacional de menores y su aplicación en los tribunales alemanes*
}

\section{Introducción}

\author{
Dr. Christoph Benicke
}

Universidad de Heidelberg, Alemania

1. La problemática de la sustracción internacional de menores

1 describir el acto en que un padre traslada el

propio hijo del país de la residencia habitual a otro país en fraccionando un derecho de

"Este es la versión escrita y ampliada de una conferencia dada el 10 de abril de 1997 en la Universidad Federal de Rio Grande de Sul.

Literatura citada en forma abreviata: Aguilar Benítez de Lugo et al., Lecciones de derecho civil internaMadrid 1995, art. 9, apartado 6, p. 282; Baer, Legal Kidnapping,ZRP 1990, p. 209; von Bar. Internationales Privatrecht, Besonderer Teil, Muenchen 1991; Boehmer, Die 14. Haager Konferenz ueber internationales Privatrecht 1980, RabelsZ 46 (1982), p. 642; Bruch, Erfahrungen mit dem Haager Uebereinkommen ueber die zivilrechtlichen Aspekte internationaler Kindesentfuehrung, FamRZ 1993, p. 745; Gonzalez Campos et al. Derecho internacional privado. Parte especial, 5a ed. Madrid 1993; Jayme, Kulturelle Identitaet und Kindeswoh im internationalen Kindschaftsrecht, IPRax 1996, p. 237; Jorzik, Das neue zivilrechtliche Kindesentfuehrungsrecht, Bielefeld 1995; Kropholler, Kommentar zum Hager Uebereinkommen ueber die Zustaendigkeit der Behoerden und das anzuwendende Recht auf dem Gebiet des Schutzes von Mindejaehrigen vom S.10.1961 en Staudinger Privatrecht, $a$ ed. Tuebingen 1994: Kropholler. Kindesentfuehrung und Grundrechte Stellungnahme des Max Planck-Instituts fuer Auslaendisches und Internationales Privatrecht, Rabels Zeiltschrift 60 (1996), p. 485; Mansel, Neues internationales Sorgerecht, NJW 1990, p. $2176 \mathrm{~s}$. Matscher La valeur internationale des jugements relatifs à la garde des enfants, Institut de Droit international, Annuaire, Vol. 66. Tome I, Travaux préparatoiresParis 1995; Pérez-Vera, Informe explicativo del convenio sobre los aspectos civiles de la sustracción internacional de menores de la Haya de 1980, citado según la traducción alemana en Drucksachen des Deutschen Bundestages 11/ 5314, p. 38; Pérez-Vera, El "menor" en los Convenios de la Conferencia de La Haya de Derecho Internacional Privado, Revista Espanola de Derecho Internacional Privado XLV 1993, p. 101; Pirrung, Kommentar zum Haager Uebereinkommen ueber die zivilrechtlichen Aspekte internationaler Kindesentfuehrungen, en Staudinger Kommentar zum Buergerlichen Gesetzbuch, 13. ed., Berlin 1994 (Staudinger/Pirrung); Shapira, Private International Law Aspects of Child Custody and Child Kidnapping Cases, en Collected Courses of The Hague ueber die zivilrechtlichen Aspekte internationaler Kindesentfuehrung vom 25.10.1980 en Muenchener Kommentar zum Buererlichen Cesetzbuch. Eraenzungsand, 2 a ed. Muenchen 1992; Silbermamn, Hague Convention on International Child Abduction: A Brief Overview and Case Law Analysis, Family Law Quarterly 1994 p. Sturm, Neue Abkommen zm Schutz entfuehrter Kinder, en Festschrift fuer Heinrich Nagel, Muenster 1987, 457; Young, The Hague Convention on Child Abduction in the Courts of England and Wales, IPRax 1996, p. 221. Abreviaciones: AG: Amtsgericht (tribunal de primer instancia); BGB: Buergerliches Gesetzbuch (código civil alemán); BVerfG: Bundesverfassungsgericht (Corte constitucional de la RFA); OLG: Oberlandesgericht (Corte de segunda instancia); Revistas: FamRZ: Zeitschrift fuer das gesamte Familienrecht, IPRax. Zeitschrift fuer Internationales Privat- und Verfahrensrecht, NJW: Neue Juristische Wochenschrif, RabelsZ: Rabels Zeitschrif fuer auslaendisches und internationales Privatrecht; ZRP: Zeitschrift fuer Rechtspolitik. 
custodia del otro padre ${ }^{1}$. La sustracción conocida bajo el termino ingles de "lega kidnapping", es un fenómeno frecuente en la actualidad debido a la intensificación de los flujos migratorios, al alto número de matrimonios mixtos y a la reducción de trámites para pasar por las fronteras ${ }^{2}$

Como las existentes normas de derecho interno y de convenios en la materia de protección de menores se mostraron ineficaces para impedir las sustracciones, varios convenios especiales fueron elaborados ${ }^{3}$. E convenio que tuvo el mayor exito en cuanto las ratificaciones y a su aplicación en la practica, es el Convenio sobre los aspectos civiles de la sustracción internacional de menores, elaborado por la conferencia de La Haya de derecho internacional privado ${ }^{4}$. Este convenio fue promulgado en la Haya el 25 de octubre de 1980.

Para una mejor comprensión del convenio, de sus reglas y su estructura, el estudio tiene que comenzar por la interrogante ¿Cuál es el problema que el convenio quiere solucionar? El contexto de la problemática a la cual el convenio quiere responder es la siguiente: Cuando un matrimonio falla surge, en muchos casos una controversia sobre el derecho de custodia de los hijos comunes. La atribución de la custodia se demuestra conflictuosa por las consecuencias que trae. A un lado la atribución de la custodia tiene efectos

${ }^{1}$ Pérez-Vera, N. 12 ss.

${ }^{2}$ Aguilar Benítez de Lugo et al., p. 78 .

3 Sturm, p. 460 s.; Alvarez González, p. 283; Convenio europeo relativo al reconocimiento y ejecución de decisiones en materia de custodia de menores, así como al restablecimiento de dicha custodia, hecho en Luxemburgo
el 20 de mayo de 1980; Convenio sobre los aspectos civiles de la sustracción internacional de menores, hecho en La Haya el 25 de octubre de 1980; Convención interamericana sobre secuestro internacional de menores, de 15 de julio de 1989; además existen convenios bilaterales; ver Boggiano, Curso de derecho internacional privado, Buenos Aires 1993, p. 420 s. para el convenio sobre protección internacional de menores entre la República Argentina y la República Orientla del Uruguay del 31 de julio de 1981; ver Jayme, IPRax 1996, 241 sobre los convenios entre Belgica y Marueco y entre Francia y Algeria.

${ }^{4}$ Matscher, p. 476.

${ }^{5}$ En derecho alemán el padre con el cual el hijo vive cumple su obligación alimenticia por procurar al hijo alojamiento y comida, mientras el otro padre tiene que prestar los alimentos en dinero, $§ 1612$ BGB. Además el hecho de cuidar un hijo joven da el derecho de pedir alimentos propios al ex-cónyuge, \& 1570 BGB
Así la atribución de la custodia es decide más radical cual de los padres puede mantener una relación personal con sus hijos. Se anade la diferencia de culturas: El hijo se cria con otro idioma y otra cultura que los del padre que no obtuvo la custodia. Estas consecuencias más radicales llevan a que los padres luchan tan arduo para obtener la custodia.

Un elemento decisivo en esta lucha es la sustracción del hijo al otro padre. Es opinión común de que la sustracción y la separación brusca de su ambiente al cual el menor está acostumbrado produce efectos negativos. Además la sustracción consiste en una infraccion de las leyes y se usa como medio para privar al otro padre de sus derechos legítimos y tiene como consecuencia el separar al menor enteramente del otro padre.

El convenio de la Haya sobre los aspectos civiles de la sustracción internacional fue concebido con el objetivo de crear mecanismos idóneos para impedir la sustracción ${ }^{6}$. Con el aumento de los números de matrimonios mixtos ${ }^{7}$ y por la tasa alta de divorcios ${ }^{8}$ en matrimonios nacionales como internacionales la sustracción de menores por un padre fue percebido como un problema frecuente y grave. Las reglas existentes fallaron al dar una solución justa e impedir las sustracciones.

El sistema del convenio solo se puede comprender ante la situación jurídica que existía sin el convenio o fuera del ámbito de aplicación del convenio. Para saber cómo se puede impedir que las sustracciones se hagan, hay que analizar las causas. Un padre sustrae al menor

${ }^{6}$ Pérez-Vera, N. 16.

7 . Jahrbuch 1996 fuer die Bundesrepublik Deutschland, p. 72.

${ }^{8}$ En Alemania fueron concluidos en total 440.244 matrimonios en el año 1994; en el mismo año fueron divorciados 166.052 matrimonios, Statistisches Jahrbuch 1996 fuer die Bundesrepublik Deutschland. 9 Ver $\underline{\text { Sturm, p. }} 461$. solamente si la sustracción le sirve como medio para obtener la custodia a su favor ${ }^{9}$. Hay que estudiar entonces por cuáles causas y de qué manera el padre puede obtener su objetivo utilizando la sustracción como medio.

Antes de entrar en este estudio quiero describir tres constelaciones típicas. Estas sirven para ejemplificar los diferentes aspectos de la problemática.

El primer caso típico es el siguiente: Los padres del menor están divorciados. El derecho de custodia fue atribuido por ejemplo a la madre brasileña que vive con el hijo en Brasil. E padre alemán tiene el derecho de visita. Aprovechándose de una visita del menor el padre se lo lleva para Alemania, donde él está viviendo. El caso se caracteriza por los hechos: Existe un arreglo judicial del derecho de custodia. El derecho de custodia fue atribuido a un padre solo. El otro padre lesiona este derecho al sustraer el menor, llevándolo al país de su residencia. Este caso puede ser nombrado como clásico.

El segundo caso típico es que los padres están todavía casados. La madre es, por ejemplo, alemana y el padre es norteamericano. El domicilio familiar está en los Estados Unidos. Por consecuencia de disputas matrimoniales la pareja se separa. Antes de que se tomará una decisión jurídica en cuanto al arreglo de la custodia, la madre regresa a Alemania llevándose a los hijos. Las características en este caso son: No existe un reglamento

\section{Casos tipícos}


judicial y que por consequencia ambos cónyuges tienen el derecho de custodia en común. Un padre se lleva el hijo a otro país antes de que una decisión en cuanto al derecho de custodia pueda tomarse en el país de la residencia habitual de la familia.

El tercer caso típico es este: Madre alemana y padre australiano viven en Australia. Los padres estan divorciados. El derecho de custodia fue atribuido a los dos padres en común. Bien que la madre está encargada de la custodia cotidiana del hijo. Por consecuencia el hijo está viviendo con la madre. El derecho de custodia del padre consiste especialmente en el derecho de visita regular y en la participación en decisiones fundamentales, como por ejemplo un cambio de la residencia habitual al extranjero. La madre deja Australia llevándose al hijo para regresar a Alemania sin el consentimiento del padre. Las características de este caso son: La existencia de un reglamento judicial de la custodia. La persona encargada del cuidado cotidiano se lleva el menor a otro país. Al otro padre fue atribuido no sólo un derecho de visita, pero también una mayor participación en la educación del menor.

\section{La problemática jurídica sin el convenio}

La situación fuera del ámbito de aplicación del convenio puede ser caracterizada generalmente como defectuosa en el sentido de que la sustracción sirve como medio eficaz para obtener el derecho de custodia y excluir al otro padre ${ }^{10}$

${ }^{10}$ Jorzik, p. 19

${ }^{11}$ von Bar, N. 335

${ }^{12}$ Staudinger/Kropholler N. 128
Para que la sustracción sirva como medio de obtener el derecho de custodia hay dos condiciones: Primera condición es que los tribunales del estado en el cual el menor fue trasladado pueden adquerir competencia para decidir sobre el derecho de custodia. Segunda condición es que transcurre un cierto lapso de tiempo antes de que un tribunal tome una decisión sobre el reparto del derecho de custodia. Cuanto más tiempo el menor permanece en la nueva residencia tanto más se integra. Esta integración del menor sirve como argumento al tomar una decisión en favor de que el menor permanezca también en el futuro en el mismo ambiente ${ }^{11}$.

\section{Competencia en el país de la nueva residencia}

Para seguir con el análisis hay que determinar cuales son las condiciones que acreditan la competencia a los tribunales del estado al cual fue trasladado el menor.

La competencia internacional en materia de custodia de menors es reglada en Alemania en primer lugar por el convenio sobre la competencia de las autoridades y la ley aplicable en materia de protección de menores hecho en la Haya en 1961. Según el art. 1 de este convenio son competentes los tribunales del estado de residencia habitual del menor. Crucial es entonces la cuestión bajo cuales condiciones el menor adquiere una nueva residencia habitual en el país al cual fue trasladado.

La residencia habitual se encuentra en el lugar donde la persona tiene el centro efectivo de su vida ${ }^{12}$. Una nueva residencia habitual se adquiere cuando la nueva residencia se ha convertido en el centro efectivo de la vida. Si una persona se desplaza con la intención de establecerse por largo plazo, el nuevo lugar se convierte inmediatamente en la nueva residencia habitual ${ }^{13}$. En el caso que un menor de edad se desplaza a otro lugar, sólo adquiere una nueva residencia habitual en seguida en este lugar, si la persona encargada de su custodia está de acuerdo con el cambio de residencia. Esto se debe a que sin el acuerdo del custor la permanencia no está asegurada en el momento de llegar. El menor adquiere una nueva residencia habitual a pesar de la oposición de custodiante a partir del momento que el lugar donde se encuentra se ha convertido en el centro efectivo de su vida. Se considera que 1 integración necesaria para esta suposición se realiza por lo general en un plazo de seis me$\operatorname{ses}^{14}$.

Así podemos concluir que despues de un plazo de seis meses, que el menor se encuentra en un país los tribunales de este país son competentes para dictar la custodia. Y los tribunales del país de la antigua residencia habitual perdieron la competencia ${ }^{15}$.

\section{Influencia de la sustracción en los criterios para la decisión sobre el derecho de custodia}

La sustracción puede producir efectos en cuanto a la decisión sobre el derecho de custodia que están a favor del sustractor. El

${ }^{3}$ Staudinger/Kropholler N. 130, 131

${ }^{14}$ Staudinger/Kropholler N. 132.

${ }^{15}$ Además segun el art. 9 del convenio sobre competencia de las autoridades y la ley aplicable en materia de protección de menores las autoridades de todo Estado en cuyo territorio se encuentre el menor pueden adoptar las medidias necesarias de protección en casos de urgencia; fuera del ámbito de aplicación de este convenio la competencia está fundada sea también por la residencia habitual sea por la nacionalidad del menor. Como el menor tiene por lo general las nacionalidades de ambos padres, los tribunales del Estado de orígen del padre sustractor son competentes por este factor.

von Bar, N. 335; Baer, p. 210

${ }^{17}$ Boehmer, p. 645; Kropholler, p. 353; Baer, p. 210; para España González Campos et al., N.55 s. 
nados en las calles de Sao Paolo. Y el juez brasileno piensa talvéz en la frialdad de la sociedad alemana y la falta de cariño y atención que el niño puede recibir.

Estas observaciones se pueden resumi de la siguiente manera: Los tribunales del país en el cual el padre sustractor ha llevado el menor se vuelven competentes para el asunto de custodia en la práctica por el sólo hecho que transcurrió un lapso de seis meses. Cuanto más tiempo el menor se encuentra en este país tanto más probable se hace que por el aparente bienestar del menor el tribunal atribuye la custodia al sustractor para que el menor no sufra un nuevo cambio de ambiente.

\section{El convenio en general}

\section{El origen}

El convenio fue elaborado por la Conferencia de La Haya del Derecho internacional privado. La sesión XIII. en el año 1976 inició los trabajos que se concluyeron en la sesión XIV en octubre del año 1980 por la formulación final y las primeras signaturas ${ }^{18}$

En el mismo año el consejo de Europa adoptó un convenio sobre la misma materia: Es el convenio Europeo relativo al reconocimiento y ejecución de decisiones en materia de custodia de menores así como al restablecimiento de dicha custodia, hecho en Luxemburgo el 20 de mayo de 1980.

${ }^{18}$ Shapira, p. 189 ss.; $\underline{\text { Boehmer, }}$ p. 643

${ }^{19}$ Boehmer, p. 646

${ }^{20}$ Matscher, 476; Pérez-Vera, Revista Española de Derecho Internacional Privado XLV 1993, p. 109; $\underline{\text { Bruch }}$, p. 745 y Silbermann, p. 16 con estadisticas sobre la aplicación en los Estados Unidos.

${ }^{21}$ La Convención interamericana sobre secuestro internacional de menores, de 15 de julio de 1989, se inspira en el convenio de La Haya aunque con ciertos particularismos regionales, ver Samtleben. Neue Interamerikanische el convenio de La Haya aunque con ciertos particularismos regionales, ver Samtleben, Neue Interamerikanische ${ }_{22}$ Staudinger/Pirrung, N. 633.

Revista da Faculdade de Direito da UFRGS, v. 20, Outubro/200I de Europa tiene efectos positivos sobre todo en cuanto al reconocimiento y a la ejecución de sentencias extranjeras de derecho de visita ${ }^{23}$.

En lo siguiente quiero presentar el reglamento del convenio de La Haya. A continuación voy a presentar unas decisiones recientes de tribunales alemanes con el fin de discutir unos problemas de la aplicación del convenio más en detalle.

3. Ambito de aplicación personal y territorial del convenio

Según el art. 4, el convenio se aplica sólo a menores de menos de 16 años de edad. $\mathrm{E}$ convenio vuelve a ser inaplicable cuando e menor cumple los 16 años durante e procedimiento de restitución ${ }^{24}$. La razon por 1 limitación de la aplicación del convenio a menores de menos de 16 años es la consideración de que para la adjudicación de la custodia de un mayor de 16 años es decisiva la voluntad del menor y que el no puede ser forzado a acepta un cambio de residencia de un padre al otro ${ }^{25}$ Como este límite de edad está fijado formalmente, el convenio no se aplica en casos de custodia de un hijo de más de 16 años que es incapacitado y por consecuencia no puede tomar una decisón propia con cual padre quiere residir ${ }^{26}$ Territorialmente el convenio se aplica, si un menor tenía su residencia habitual en un paí miembro y se encuentra después de la sustracción en otro país miembro del convenio.

\section{Mecanismos del convenio}

El objetivo del convenio es de asegurar el regreso inmediato del menor, para así restau-

${ }^{23}$ Pirrung, Sorgerechts- und Adoptionsuebereinkommen der Haager Konferenz und des Europarats, RabelsZ 57 (1993), 124, 141 .

${ }^{24}$ Staudinger/Pirrung, N. 648

${ }^{25}$ Pérez-Vera, N. 77.

${ }^{26}$ Staudinger/Pirrung, N. 648

${ }^{27}$ Ver Pérez-Vera, Revista Española de Derecho Internacional Privado XLV 1993, p. 108. ${ }^{28} \underline{\text { Siehr, N. }} 62$. rar la situación anterior a la sustracción. Por el retorno inmediato del menor el convenio intenta de que el sustractor no pueda influenciar en su favor, los hechos decisivos para la atribución de la custodia por una decisión judicial.

El fin del convenio es en este aspecto a un lado la restauración de la situación anterior en el caso concreto. Además tiene el objetivo de producir efectos preventivos: Viendo que la sustracción no sirve como medio de influenciar la atribución de la custodia, el interés de usarlo desaparecerá. Como una sustracción siempre es capaz de producir daños para el menor, el objetivo del convenio, de impedir de una manera preventiva las sustracciones, es primordial ${ }^{27}$.

Los mecanismos del convenio para lo-

En art. 12 el convenio constata el derecho de pedir la restitución del menor. Este derecho está resforzado por una cooperación estrecha de las autoridades centrales que los paises miembros tienen que instalar. Además, el art. 16 prohibe a las autoridades competentes del esado de la residencia actual del menor, de tomar una decisión sobre la cuestión de fondo de los derechos de custodia desde el momento que están informados de un traslado o retención ilícitos. Esta regla tiene como fin, que la decisión de restitución no sea impedida por una decisión que atribuye el derecho de custodia al sustractor ${ }^{28}$. El convenio tiene como fin, que el derecho de custódia del estado de la residencia habitual del menor antes de la sustracción, se respete. Y si una nueva decisión sobre la custodia se hace necesaria, ésta tiene que grar estos fines son los siguientes: 
hacerse en este mismo estado. El convenio no tiene como objeto generar la cuestión de fondo de los derechos de custodia ni la cuestión de reconocimiento del derecho de custodia establecido por la ley o por decisión judicial. El reglamento sólo visa la restauración de la situación que existía antes de la sustracción ${ }^{29}$.

\section{La restitución}

El núcleo del convenio es el art. 12 que contiene el derecho de pedir, que la autoridad competente en el estado donde se halle el menor ordene la restitución inmediata del menor. En cuanto a las condiciones, para que la restitución se ordene, el convenio hace la diferencia si un período inferior o mayor a un año ha transcurrido desde el momento en que se produjo la sustracción y la fecha de la iniciación del procedimiento de restitución.

\section{Traslado o retención ilícitos}

Condición común es que el menor ha sido trasladado o retenido ilícitamente en el sentido previsto en el artículo 3.

\section{El art. 3 dice :}

El traslado o la retención de un menor se considera ilícitos:

a) Cuando se hayan producido con infracción de un derecho de custodia atribuido, separada o conjuntamente, a una persona, a una institución o a cualquier otro organismo, con arreglo al Derecho vigente en el Estado en el cual el menor tenía su residencia habitual inmediatamente antes de su traslado o retención; y

\footnotetext{
${ }^{29}$ Sturm, p. 468; Kropholler, p. 355

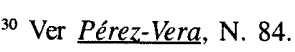

${ }^{31}$ Silbermann, p. 17.
}

b) Cuando este derecho se ejercía en forma efetiva, separada o conjuntamente, en el momento del traslado o de la retención, o se habría ejercido de no haberse producido dicho traslado o retención.

\section{a) Derecho de custodia}

Primer elemento es, que existía un derecho de custodía. Este puede ser atribuido a los dos padres, a otras personas o a una institución estatal o privada. Por razones de simplificar trataré en lo siguiente solo el caso más frecuente, que un padre lesiona el derecho de custodia del otro padre.

El caso está incluido, que los padres están casados y el derecho de custodia les está atribuido a los dos en común por la ley. Está protegido también el derecho de custodia atribuido por vía judicial a uno o a los dos padres después de la separación o del divorcio ${ }^{30}$.

El art. 5 define la noción de derecho de custodia como el derecho relativo al cuidado de la persona menor y, en particular, el de decidir sobre su lugar de residencia. La noción de custodia en el convenio es autónomo y no tiene que corresponder a nociones parecidas en los diferentes ordenes jurídicos nacionales ${ }^{31}$.

\section{b) La ley aplicable para determinar el derecho de custodia}

La ley aplicable para determinar si un derecho de custodia existía, es la ley del estado de la residencia habitual del menor. Según el art. 14, ésto vale también para las decisiones judiciales o administrativas, sin que éstas tengan que ser reconocidas en el Estado requerido.
Para la constatación, si un derecho de custodia existía, el juez del estado requerido en carga del caso tiene que apreciar la existencia de un derecho de custodia como haría un juez en el país de la residencia habitual del menor. Las reglas normales del derecho internaciona privado o las reglas sobre el reconocimiento de laudos extranjeros no se aplican en la rama de convenio.

El convenio no tiene como objeto directo el reconocimiento de decisiones sobre la custodia. Como el tribunal del estado requerido tiene que apreciar la existencia de un derecho de custodia como se hace en el estado de la residencia habitual del menor, una decisión sobre la custodia dictada en este estado antes de la sustracción es determinante para el procedimiento de la restitución ${ }^{32}$.

\section{c) Infracción}

Para que el traslado o la retención sean ilícitos, el traslado o la retención tienen que haberse producido con infracción de un derecho de custodia.

Una infracción significa, que el ejercicio del derecho de custodia fue obstaculizado por el acto de traslado o de retención. Sea que le impide a la otra persona el ejercer la totalidad o una parte del derecho de custodia. Esto equivale también para el caso, en que el derecho de custodia está atribuido a los dos padres en común. Al excluir al otro padre del ejercicio de derecho de custodia, el padre que se lleva el menor lesiona este derecho de custodia ${ }^{33}$

${ }^{32}$ Bruch, p. 746.

${ }^{33}$ Staudinger/Pirrung, N. 645

${ }^{34}$ Silbermann, p. 20; Staudinger/Pirrung, N. 691; Young, p. 222

${ }_{35}^{35}$ Staudinger/Pirrung, N. 643

${ }^{36}$ House of Lords (England) In re J. (a minor) (Abduction: Custody Rights)[1990] 3 W.L.R. 492, citado según Bruch, p. 746.

${ }^{37}$ Young, p. 222 y el caso Re B (A Minor) (Abductio) [1994] 2 FLR 249.
El art. 15 constata que la autoridad en cargo de un procedimiento de restitución puede exigir que el demandante obtenga de las autoridades del estado de residencia habitual del menor, una decisión o una certificación que acrediten que el traslado o retención del menor era ilícito. No queda claro si tal decisión o certificación tiene un caracter vinculante para la autoridad que decide sobre la restitución. A un lado un caracter vinculante promoviera una decisión rápida sobre la restitución. Al otro lado hay que diferenciar entre la descripción del derecho que tenia el padre según el orden jurídico del estado de la residencia habitual del menor y su clasificación según las reglas del convenio. Esta última decisión incumbra a la autoridad competente para dictar sobre la restitución ${ }^{34}$.

El derecho de custodia tiene que haber sido existente en el momento del traslado ${ }^{35}$. El convenio no se aplica en principio cuando el padre encargado de la custodia deja el estado de la residencia habitual y solo después una

Los casos se han monstrados problemáticos, cuando los padres vivían en una unión de hecho y ejercían la custodia en común y por la ley la custodia estaba solamente atribuida a la madre. Cuando los padres se separan y la madre se lleva al hijo, se plantea la cuestión si la del padre en el sentido del art. $3^{37}$.

El texto literal del art. 3 habla expresamente de la infracción de un derecho de custodia. Tomando en cuenta el objetivo del decisión transfiere la custodia al otro padre ${ }^{36}$. madre lesiona un derecho de custodia por lado 
convenio, de protejer al menor de no perder un padre por un acto unilateral del otro padre y de no permitir a un padre de utilisar la sustracción como medio de privar al otro padre de la custodia, un concepto amplio del derecho de custodia parece más adecuado. Si en el estado de la residencia habitual existe la posibilidad, que la custodia sea atribuida al padre del hijo extramatrimonial después de la separación de los padres a pesar de que éste no ha tenido un derecho formal de custodia. El caso equivale en todo aspecto de los objetivos del convenio al caso que los padres tenían formalmente und derecho de custodia en común.

Si el padre del hijo extramatrimonial no puede obtener un derecho de custodia, el solo hecho de que éste ha ejercido la custodia en la práctica, no es suficiente para la protección por el convenio. Bien que el interés del menor puede exigir la continuación de la relación con el padre, la misma ley del estado de la residencia habitual no sirve como base legal para la custodia del padre.

\section{d) Ejercicio efectivo del derecho de custodia}

El traslado o la retención solo son ilícitos, cuando el derecho de custodia que fue violado se ejercía de forma efectiva en el momento del traslado o de la retención (art. 3 lit. b, 13 lit

a). El convenio tiene la intención de proteger un derecho actualmente ejercido y no un derecho, que existe sólo de manera formal. Un tribunal alemán negó la restitución por falta de ejercicio efectivo del derecho de custodia en un caso, que el padre no había intentado du-

${ }^{38}$ Kammergericht Berlin 13.12.1995, FamRZ 1996, 691

${ }^{39}$ Ver sobre los problemas que se plantean en este sentido Staudinger/Pirrung, N. 682 y las decisiones ingleses Toportadas por Young, p. 222

${ }^{40}$ Mansel, 2177.

${ }^{41}$ Silbermann, p. 25.

Revista da Faculdade de Direito da UFRGS, v. 20, Outubro/2001 rante dos años entrar en contacto con su hija de 4 años de edad ${ }^{38}$.

\section{e) Consentimiento o aceptación del traslado}

No existe la obligación de dictar la restitución, si la persona a cargo de la cusodia había consentido o posteriormente aceptado el traslado o la retención (art. 13 lit. a) ${ }^{39}$.

\section{Excepciones de la obligación de restitución}

El convenio hace la diferencia en cuanto a las excepciones de la restitución del menor según el tiempo transcurrido entre el momento, que se produjo el traslado o la retención del menor y la iniciación del procedimiento ante la autoridad judicial o administrativa. Cuando este período es menos de un año la restitución del menor puede ser negada sólo por causas extremamente graves ${ }^{40}$. El éxito del convenio depende esencialmente en que las excepciones sean interpretadas de una manera restringida ${ }^{41}$. El efecto preventivo sólo se puede realizar, si la sustracción no favorece el sustractor.

\section{a) Riesgo de peligro}

Cuando la solicitud de restitución se ha iniciado dentro del plazo de un año sólo puede ser negada, si la persona que se opone a la restitución demuestra que "Existe un grave riesgo de que la restitución del menor lo exponga a un peligro físico, psíquico o de cualquier otra manera ponga al menor en una situación intolerable" (art. 13).

\section{(1) Grado del riesgo}

Por el fin del convenio de impedir la sustracción ilegal de los menores, el grado de riesgo para un peligro físico o psíquico tiene que ser muy alto. Los inconvientes, que resultan de cada traslado de un menor de un estado a otro con los cambios inherentes en cuanto al idioma y al ambiente cultural, no justifican la negación de la restitución. Si no, la sustracción siempre tendría éxito. La prevención general que el convenio tiene como objetivo, no se podría realizar. El convenio da preferencia al interés general de los menores, que consiste en la prevención de las sustracciones. Por este motivo el convenio acepta que el menor en un caso concreto tiene que sufrir el inconveniente de un cambio reiterado ${ }^{42}$.

Como excepción, fue reconocido e peligro actual no sólo hipotético, de que el menor fuera maltratado de obra en el país, en el cual la restitución se efectuará, sea por el mismo padre o la misma madre o por una tercera persona, por ejemplo, la nueva pareja de un padre $^{43}$.

La otra alternativa del art. 13 lit. b es e riesgo, que la restitución ponga al menor de cualquier otra manera en una situación intolerable. Esta excepción tiene el sentido de una clausula general para impedir una violación

${ }^{42}$ Pérez-Vera, No. 34; Siehr, N. 46; Staudinger/Pirrung, N. 683; Bruch, p. 751; Jayme, IPRax 1995, 118; Kropholler, RabelsZ 60 (1996), p. 490; Klein, IPRax 1997, 106, 109; BVerfG, 15.2.1996, FamRZ 1996, p. 405; por la oposicón de los menor); OLG Hamburg 16.1.1996, FamRZ 1996, 685. Court of A ppeal (England) casos citas

${ }^{43}$ AG Charlottenburg 7.10.1992, citado por Staudinger/Pirrung, N. 683.

${ }^{44}$ BVerfG 15.8.1996, NJW 1996, 3145; OLG Nuernberg 13.9.1993, IPRax 1995, 118; ver también las decisiones citadas por Bruch, p. 751; por Silbermann, p. 28 s. y por Young, p. 224.

${ }^{45}$ Bruch, p. 752; Staudinger/Pirrung, N. 635

${ }^{46}$ P.v.P. High Court of Justice (Manchester Fam. Div.) 19.9.1989 citado por Bruch, p. 751; decisiones de tribunales ingleses reportados por Young, p. 224; Kropholler, RabelsZ 60 (1996), 491 ss, con resumen de la jurisprudencia en Suiza, Estados Unidos, Inglaterra y Francia.

${ }^{47}$ Navaro v. Bullock, Calif. Superior Ct., Placer County, N. 86481 (1.9.1989) citado por Bruch, p. 753

Revista da Faculdade de Direito da UFRGS, v. 20, Outubro/200 de los intereses fundamentales del menor. Pareú ámo se aplica en la práctica. Tiene excepción por peligro físico o psíquico.

En el caso, que el menor fue sustraido por la persona que estaba primeramente los padres están todavía casados y la madre que cuidaba al hijo, deja el hogar llevándose al paca edad. (a) enordenaron la restitución con la convicción de - la madre se va a deplazar junto con el metribunales aplazaron el procedimiento para dar posibilidad de procurar condiciones adecuadas, para que la madre pudiera regresar con el mede un nuevo cambio fue causado primordialmente por la sustracción ilícita, efectuda por la misma madre ${ }^{47}$ madre. Esto vale sobre todo en casos de niños 
Por lo general esta actitud flexible me parece muy adecuada para realizar el fin del convenio. De esta manera se puede excluir el riesgo para el menor y realizar la restitución. La limitación de las excepciones de dictar la restitución es decisiva para el éxito del convenio.

\section{(3) Carga de prueba}

El convenio dispone, que la restitución solo se pueda negar, cuando el padre que se opone a la restitución, demuestra la existencia de una de las mencionadas excepciones a la restitución. La prueba está a cargo del padre, que se opone a la restitución. El tribunal no tiene que abrir investigaciones de oficio ${ }^{48}$. Puras aserciones del sustractor sobre peligros existentes no pueden ser suficientes para obligar al tribunal de entrar en investigaciones. Sino el fin del convenio de asegurar la restitución en corto tiempo podría ser impedido por el sustractor. El sustractor tiene que mostrar pruebas concretas y concluyentes ${ }^{49} . \mathrm{El}$ art. 13 par. 3 establece, que al examinar un posible peligro para el menor, el tribunal tendrá en cuenta la información que la autoridad central u otra autoridad competente del lugar de residencia habitual del menor proporcione sobre la situación social del menor.

La decisión sobre la restitución resulta ser una tarea muy difícil y compleja para el tribunal. Debido a que existe la contrariedad entre el fin preventivo del convenio y la protección del menor en el caso específico.

\section{b) Oposición del menor al dictar la restitución}

En el art. 13 el convenio reconoce también la oposición del menor como causa para

${ }^{48}$ Mansel, 2177.

${ }^{49}$ Kropholler, RabelsZ 60 (1996), 497.

${ }^{50}$ Boehmer, 650.

${ }^{51}$ OLG Celle 20.10.1994, FamRZ 1995, 955.

${ }^{52}$ Casos citados por Bruch, p. 753.

Revista da Faculdade de Direito da UFRGS, v. 20, Outubro/200I negar la restitución. La oposición se toma en cuenta, cuando el menor haya alcanzado una edad y un grado de madurez en que resulta apropiado tener en cuenta sus opiniones. El sentido de esta regla es, que el menor tiene el derecho que su propia voluntad sea respetada. $\mathrm{El}$ menor no es objeto del procedimineto. $\mathrm{El}$ convenio tiene por fin primordial el bienestar de los menores. La madurez del menor es el punto esencial. Ella se puede considerar únicamente en el caso específico.

El convenio determina la edad apropiada para tomar en cuenta la opinión del menor com condición acumulativa. No se fijó una edad mínima absoluta. Como consecuencia, todo depende de la madurez del menor en el caso específico. Por lo general, siempre se va a tomar en cuent la oposición de un menor con 14 o más años ${ }^{50}$

Pero muchas decisiones han respetado la voluntad de niños mucho más jóvenes. Por ejemplo tribunales alemanes han acepatado la voluntad de dos hermanos con 7 y 9 años $^{51}$, en otro caso la oposición de una niña con 7 años o hasta la oposición contra la restitución de 2 hermanos con 5 y 6 años ${ }^{52}$. La opinión del menor es también un factor para apreciar si la restitución causa un daño psíquico al menor.

El problema, que se plantea en este aspecto, es la influencia que tiene el sustractor en la opinión del niño. A un lado, es importante respetar la opinión del menor, ya que él tiene propios derechos y no puede ser tratado como el objeto de los intereses y derechos de los padres. Al mismo tiempo, el convenio perdería su eficacia, si el sustractor podría manipular la situación en su favor utilizando su influencia en la opinión del menor
Además, la oposición del menor de vivir con el otro padre, no justifica la negación de la restitución, argumantación errona que se encuentra en varias decisiones. La opinión de menor, con cual padre quiere vivir, tiene que se tomado en cuenta en el procedimiento sobre la custodia $^{53}$. La restitución no significa necesariamente que el menor sea entregado al otro padre. La restitución tiene como objetivo a hacer posible que el procedimiento sobre la cuestión de fondo se lleva a cabo en el estado de la residencia habitual del menor antes de la sustracción.

\section{c) Cláusula de ordre public}

El art. 20 constata que la restitución podrá denegarse cuando no lo permitan los principios fundamentales del estado requerido en materia de protección de los derechos humanos y de las libertades fundamentales. Esta cláusula de ordre public es formulada de una manera más estrecha que usual ${ }^{54}$. Al lado de art. 13, esta norma tiene un ámbito de aplicación muy restringido. No se conoce un caso en el cual el art. 20 justificó la negación de la restitución ${ }^{55}$.

\section{La restitución después de un lapso de un año}

En el caso, de que los procedimiento para la restitución se hubieran iniciado después de la expiración del plazo de un año desde e momento de la sustracción, el tribunal siempre puede ordenar la restitución. Pero según el art.

${ }^{53}$ Bruch, p. 753, nota 60; Silbermann, p. $30 \mathrm{~s}$

${ }^{54}$ Mansel, 2177; Shapira, p. 197 s.

${ }_{55}$ Staudinger/Pirrung, N. 698.

${ }^{56}$ Re N (Minors Abduction [1991] 1 FLR 413, citado por Young, p. 222

57 Ver la argumentación de OLG Bamberg 18.7.1994, FamRZ 1995, 305; para una interpretación restringida de la noción ,integrado“ Siehr, N. 44.

${ }^{58}$ OLG Bamberg 18.7.1994, FamRZ 1995, 305.

${ }^{59} \underline{\text { Jorzik, }}$ p. 51.
12 par. 3, el tribunal puede negar la restitución en este caso si queda demostrado que el menor ha quedado integrado en su nuevo ambiente. Esta disposición abre la posibilidad de reclamar la integración del menor en el ámbito de la nueva residencia.

Tribunales ingleses se han mostrados restringidos en aceptar esta excepción de la restitución. A un lado, un menor de poca edad depende primordialmente de la relación con el padre que le está cuidando. La integración de la madre sustractor no fue tomado como suficien-

Si se trata de menores de más edad que van al jardin de la infancia o a la escuela, la integración en el ambiente de la nueva residencia es la regla ${ }^{57}$. Así la observancia del plazo de un año es decisiva. La restitución que e solicita dentro de un año tiene una alta posibilidad de ser dictada. Mientras que una solicitud después de este lapso tiene poca chance de ser atribuida. Para que el procedimiento se pueda iniciar en este plazo, la ayuda que las autoridades centrales pueden prestar son de suma importancia. Decisivo para este lapso no es la recepción de la solicitud de autoridad competente para dictar sobre la restitución ${ }^{58}$

\section{El procedimiento}

El procedimiento para lograr la restitución es muy flexible y se caracteriza por la ayuda de las autoridades centrales ${ }^{59}$. La persona o la organización, que tenía un derecho te para suponer la integración del hijo ${ }^{56}$. restitución en la autoridad central, pero en la 
de custodia que fue lesionado por la sustracción, puede solicitar la iniciación de los trámites de restitución. Esta solicitud puede se dirigida a la autoridad central del estado de 1 residencia habitual del menor (art. 8). Esta autoridad central transmitirá la demanda a la autoridad central del estado, en el cual se supone que el menor se encuentra (art. 9).

La autoridad central del estado dond se encuentre el menor, adoptará o hará que se adopten todas las medidas adecuadas encaminadas para conseguir la restitución voluntaria del menor o a facilitar una solución amigable (art. 10, 7 lit. c). Si una solución voluntaria no se consigue, la autoridad centra incoará o facilitará la apertura de un procedimiento judicial (o administrativo) para conseguir la restitución del menor (art. 7 lit. f). En este caso concederá o facilitará la obtención de asistencia judicial y jurídica (art. 7 lit. g).

El demandante no está excluido de dirigirse directamente a la autoridad central de estado, donde se encuentra el menor o de iniciar directamente el procedimiento de restitució por la autoridad judicial o administrativa competente en el estado de la residencia acutal de menor (art. 29). En la práctica, la vía de 1 solicitud mediante la autoridad central del estado de la residencia habitual del menor es lo más efectivo. La autoridad central acumula con 1 práctica experiencia. Se establece una costumbre de contactos directos y personales con las demás autoridades centrales. De gran ayuda es también la mediación de las autoridades centrales para disminuir los obstáculos de llevar un proceso en otro país. Antes, muchos intentos de demandantes fallaron por el consumo de tiempo que causan la búsqueda de asistencia judicial y otras dificultades de un proceso en un país extranjero.
La colaboración y la ayuda de las autoridades centrales son los puntos claves para que el procedimiento de la restitución se pueda iniciar y llevar a cabo en un lapso de tiempo corto. La brevedad del procedimiento es esencial para la realización del objetivo del convenio: Cuanto más tarde el procedimiento y por esto cuanto más el menor se quede en la nueva residencia, tanto más causas pueden ser invocadas contra una restitución.

El convenio no prescribe un cierto procedimiento para el proceso de restitución delante la autoridad judicial o administrativa. El art. 11 constata solamente que las autoridades judiciales (o administrativas) actuarán con urgencia en los procedimientos para la restitución de los menores. Cada estado contractante tiene que determinar que procedimiento se aplica. El procedimiento tiene que permitir, que la decisión de restitución se pueda llevar a cabo dentro un plazo corto. El plazo de seis semanas del art. 11 par. 2 puede servir como norma. El art. 11 par. 2 determina que el demandante y la autoridad central del estado requerido tienen el derecho de pedir una declaración sobre las razones de la demora, si una decisión no se hubiera tomado dentro de seis semanas a partir de la fecha de la iniciación de los procedimientos.

En Alemania son competentes para decidir sobre la demanda de restitución los departamentos especiales encargados de asuntos de derecho de familia en los tribunales de la primera instancia. Las sentencias de este tribunal pueden ser apeladas delante del tribunal regional superior por el recurso imediato en un plazo de dos semanas ${ }^{60}$

60 §§ 6, 8 Ausfuehrungsgesetz, $\S \S 22,28$ Gesetz ueber die Angelegenheiten der freiwilligen Gerichtsbarkeit (FGG) en caso de divergencias de cuestiones de derecho entre diferentes tribunales superiores regionales la corte federal suprema decidará del caso por presentación del tribunal superior regional.

Revista da Faculdade de Direito da UFRGS, v. 20, Outubro/2001

\section{Recientes decisiones de tribunales alemanes}

Después de haber mostrado la problemática a la cual responde el convenio y las soluciones previstas por éste (la restitución rápi da bajo pocas condiciones y la colaboración internacional por medio de autoridades centrales) quiero ejemplificar unos problemas, analizando dos casos recientes que fueron decididos por la corte constitucional de Alemania en una manera casí opuesta.

\section{Primera decisión de la Corte Constitucio- nal}

En la primera decisión, la Corte Constitucional tenía que solucionar el siguiente caso $^{61}$ :

El marido, norteamericano, y la esposa, lemana, vivían juntos en Utah en los Estados Unidos. El hijo común nació en el año 1989. En el año 1994 los cónyuges se divorciaron. El derecho de custodia fue atribuido a la madre. Al padre fue atribuido el derecho de contacto permanente y seguido y el derecho de ser consultado de cuando se quiera cambiar la residencia en los Estados Unidos de un estado a otro. En caso de cambio de vivienda en el mismo estado existía la obligación de los excónyuges de informar al otro. La madre tuvo el derecho de llevarse al menor para Alemania en el tiempo de vacaciones de verano. Al final del año 1994 la madre salió de los E.U. junto con su hijo para domiciliarse en Alemania. El padre obtuvo la decisión de un tribunal en los E.U. que le atribuyó a él solo el derecho de custodia. El mismo tribunal constató por una decisión que los derechos del padre que le habían sido

${ }^{61}$ BVerfG 15.8.1996 (3. Kammer des Zweiten Senats), IPRax 1997, 124 = NJW 1996, 3145; caso y decisión Dents), IPRax 1997, $123=$ FamRZ 1996, 405

${ }^{62}$ BVerfG 17.3.1995 (1. Kammer des 1. Senats), IPRax 1997, 121 = FamRZ 1995, 663 atribuidos antes del traslado del menor, tienen que ser calificados como el derecho de custodia en el sentido de los art. 3 y 5 del convenio de la Haya. Por la solicitud del padre el tribunal alemán de primera instancia ordenó la restitución de menor. La decisión fue mantenida en la segunda instancia y el recurso a la Corte Constitucional quedó sin éxito.

El punto de salida es la observación de la Corte constitucional que la protección del menor contra la sustracción plantea cuestiones que toquen los intereses y derechos fundamentales del menor y de ambos padres. E interés del menor siempre es prescindible al de los padres. El fin del convenio es que la restitución se efectue lo más rápido posible. Este fin está orientado hacía el bienestar de menor. El bienestar en un sentido general demanda la restitución para desanimar a los padres de cometer sustracciones. El traslado causado por la restitución es inconveniente para e menor, pero está justificado por los efectos preventivos que tiene. De esa forma, futuras tendencias de sustracciones se deciminan. La protección de los niños en general reclama este efecto preventivo. El fin del convenio justifica una aplicación estrecha de las excepciones de la restitución. Los intereses del menor en juego en el caso concreto son protegidos en una manera suficiente por el art. 13 del convenio.

\section{Segunda decisión de la Corte Constitucio-}

Lo que la Corte Constitucional no toma en cuenta en esta decisión son los intereses de la madre, de no regresar a los Estados Unidos. Estos intereses fueron más importantes en otra decisión de la Corte Constitucional, tomada por otra cámara ${ }^{62}$. 
Los hechos de este caso son muy parecidos al recién mencionado. Se trataba también de una pareja mixta: El esposo norteamericano, la esposa alemana. La pareja se había casado en el año 1988 y vivían en los Estados Unidos. En febrero del año 1993 nació la hija común. En junio del mismo año, el padre dejó el hogar. Desde este tiempo los cónyuges vivían separados. El padre siguió viendo a la hija. En relación con las negociaciones sobre el reglamento de las consecuencias de la separación y de un divorcio, el padre ofreció a la madre ventajas financieras en el caso que se quedará con la hija en los Estados Unidos.

La madre dejó los E.U. antes de que una decisión sobre la custodia fuera tomada llevándose a la hija y se instaló en la casa de sus padres. El padre obtuvo en los Estado Unidos una certificación de que el traslado lesionó el derecho de custodia del padre. El padre no tenía la intención de obtener el derecho de guarda. Más bien quería, que el derecho de custodia se les atribuyera a los dos padres, mientras que la guarda cotidiana se le atribuyera a la madre. Por consecuencia de tal reglamento la madre tendría que permanecer y criar la hija en los Estados Unidos.

El tribunal de primer instancia negó la restitución con el argumento, de que el padre no ejercía efectivamente el derecho de custodia en el momento de que la madre dejó los Estados Unidos. El tribunal superior regional ordenó la restitución, argumentando que lo inconveniente de un regreso para la niña se puede evitar por la compaña de la madre.

La Corte Constitucional federal, a la cual la madre recurrió en nombre propio y en nombre de la hija, decidió en el procedimiento provisional que la restitución no se efectuara ${ }^{63}$ La restitución podría lesionar el derecho funda-

mental de la niña al respeto de su derecho de la personalidad. La separación de un niño de poca edad de la madre que la estaba cuidando hasta el momento es muy probable de causar daños severos. La Corte Constitucional constata, que en cuanto a la posibilidad de que este daño puede evitarse por la compaña de la madre había que tomar en cuenta las razones que la madre puede invocar en contra de un regreso.

\section{Analisis de las decisiones}

Las dos deciciones se contradicen en alto grado. Hay que analizar que solución favorce el convenio.

\section{a) Caso clásico}

Para ésto, es importante ver que estos casos no son los casos clásicos, que el convenio visaba. El caso clásico es que el padre que no tiene el derecho de custodia quita el hijo al otro padre que lo estaba cuidando ${ }^{64}$. En este caso no hay problema en cuanto a la infracción de un derecho de custodia y en que la restitución se realice con la entrega del menor al padre que lo estaba cuidando antes de la sustracción.

Todavía el segundo caso típico que fue descrito arriba, no causa problemas en la aplicación del convenio. Es el caso, que un padre se lleva a los hijos antes de que una decisión sobre el derecho de custodia haya sido tomada. El derecho de custodia que fue lesionado existía en pleno derecho. La restitución significa un regreso provisional del padre y del hijo para que se puedan efectuar los tramites de divorcio y de atribución de derecho de custodia.

La problemática que existe en este caso ya se mencionó. Si era por ejemplo la madre que

“3 La decisión final fue tomada de una cámara del segundo senato, BVerg 10.10.1997, IPRax 1997, 123; esta decisión rechazó el recurso de la madre con la consecuencia que la restitución se podía efectuar. 64 González Campos et al., N.55 se llevó a un hijo de poca edad, la restitución podría cometer un grave daño si el hijo no fuera acompanado de la madre. Pero fue mostrado arriba que los tribunales han encontrado medidas para hacer posible que la madre regrese temporalmente con el hijo. Es muy importante ver que según el convenio la restitución no puede ser negado con el argumento que e derecho de custodia se atribuyera con certeza a la madre que sustrajó el menor. El objetivo preventivo del convenio exige que la decisión sobre la atribución del derecho de custodia se tome en el estado de la residencia habitual del meno antes del traslado.

\section{b) Particularidad de los dos casos}

Los dos casos de las decisiones mencionados se caracterizan por un aspecto adicional. La atribución del derecho de custodia se ha hecho o se iba a hacer de la manera que la madre tiene la guarda actual y cotidiana del menor, mientras los dos padres tienen el derecho de custodia en común. Este derecho de custodia consiste por parte del padre en el derecho de visita resforzado por el hecho de que la madre puede tomar ciertas deciciones, como especialmente el cambio de residencia a un otro estado, sólo con el consentimiento de este padre.

La primera cuestión que se plantea es, si el derecho del padre puede ser calificado como un derecho de custodia, en el sentido de convenio. Sólo la infracción a un derecho de custodia da camino a una restitución. Si el otro padre tenía solamente un derecho de visita, e padre no puede oponerse a un cambio de residencia. El convenio no proteje el interés del padre, que solamente tiene un derecho de visita, de vivir cerca de su hijo. El derecho de visita no está protegido contra el obstáculo de ejecerlo

${ }^{65}$ Pérez-Vera, N. 65; Young, p. 222

${ }^{66}$ En este sentido dictaron la mayoría de los tribunales como reportado por Silberman, p. 17 s. (por ejemplo Court 66 En este sentido dictaron la mayoría de los tribunales como reportado
of Appeal in England [1989] 1 FLR 403 (C.A.) y por Young, p. 222 .

${ }^{67}$ Bruch, p. 752; Young, p. 222. sobre una larga distancia ${ }^{65}$. La dicción literal del convenio es bien claro en cuanto a esta cuestión. El art. 5 lit. a determina, que para los efectos del convenio, el derecho de custodia comprenderá el derecho relativo al cuidado de la persona del menor y, en particular el de deci-

Pero parece que a pesar de esta definición, los redactores no tenían consciencia de los problemas que surgen por este tipo de distribución del derecho de custodia ${ }^{67}$. Considerando un derecho que no contiene el cuidado de la vida cotidiana pero el derecho de participar en la decisión sobre la residencia del menor como derecho de custodia en el sentido de la convención causa problemas en dos aspectos.

A un lado se plantea la cuestión de que manera la restitución se efectua en un caso, que, por ejemplo la madre que tiene el derecho de guarda sustrajó el menor. La restitución no se puede realizar sin problemas por la entrega al padre. El derecho de éste no contiene la guarda cotidiana. Además en caso de niños de poca edad el bienestar del menor exige la continuación del cuidado por la misma persona, es decir en muchos casos la permanencia con la madre.

En este sentido se hace claro que el derecho de custodia del padre consiste en tal caso en realidad sólo en un derecho de visita reforzado. En la mayoría de los casos los tribunales pueden encrontrar una solución. Ya fue mencionado la posibilidad del tribunal de hacer entender al demandante que la restitución sólo se puede dictar si éste procura las condiciones adecuadas para que la madre pueda regresar con el menor.

Por ésto, las observaciones del tribunal superior de Berlin eran erróneas, cuando pensaba que la restitución no se podía dictar dir sobre su lugar de residencia ${ }^{66}$ 
porque la madre que sustrajo tenía el derecho de guarda cotidiana y que por consecuencia no se podía entregar el menor al padre ${ }^{68}$. El tribunal no prestó atención de que la restitución no significa necesariamente la entrega del meno al otro padre. La restitución visa a reestablece la situación que existía antes de la sustracción. Lo importante es por consecuencia que el menor toma de nuevo residencia en el país del cua fue sustraído. Se encuentran con frecuencia decisiones que ordenan la restitución y hacen entender a la madre, que debe regresar con e hijo, sobre todo por haber sido ella la causante de la situación al sustraer al menor. El hecho de que el otro padre no quiere o no puede se encargado del cuidado cotidiano no impide la restitución, cuando la madre puede regresar con el menor.

Esta observación lleva a la segunda problemática: De qué manera el tribunal tiene que tomar en cuenta los argumentos de la madre que no quiere regresar por sus propios intereses? Los intereses de la madre de no regresar tienen que tomarse en cuenta para apreciar, si existe el peligro de un daño que la restitución podría ocasionar. Si la situación de la madre es que no puede acompañar al menor los efectos de la separación en consecuencia de la restitución pueden causar la negación de la restitución. Un tribunal alemán de prime instancia negó la restitución por el peligro de un daño grave para el menor porque no veí posible que la madre que había sustraido al menor regresara a Australia. La madre se había casado otra vez y tenía un bébé recien nacido en el nuevo matrimonio ${ }^{69}$

En casos que el regreso sea posible, la tendencia de ordenar la restitución obliga a la madre de hecho, de regresar con su hijo al país

de la residencia anterior. Los intereses de la madre de no volver a vivir en el país, no necesitan ser tomados en cuenta para la decisión de la restitución. La idea de la decisión sobre la restitución, es que reestablece solamente la situación anterior de la sustracción y no tiene efectos sobre la decisión final sobre el reparto de la custodia. Estos intereses de la madre tienen que ser tomados en cuenta en el procedimiento sobre el reparto de la custodia que se va a llevar a cabo en el estado de la residencia anterior.

En la realidad, la separación total de la decisión sobre la restitución según el convenio y la siguiente decisión sobre el fondo de la custodia, solo se va a realizar, si el tribunal que decide sobre la restitución tiene la convicción que el tribunal que decide sobre la custodia en fondo, no tomará una decisión parcial en favor del padre nacional del mismo estado. Este problema se pone especialmente en tal caso que a la madre fue atribuido el derecho de custodia y la guarda cotidiana, pero con la restricción de que no puede salir del estado de la residencia habitual de la familia sin el consentimiento del excónyuge.

La restitución del menor significa que la madre tiene que regresar con el menor al país de la residencia habitual antes de la sustracción. Si en este país la decisión sobre el derecho de custodia es matenido de la misma manera, la madre queda obligada de permanecer en este país.

Esto puede ser justificado con el interés del menor de permanecer en el mismo país, donde él se crío hasta el momento de la sustracción. Además se reconoce el interes del menor de mantener relaciones estrechas con los dos pa-

${ }^{68}$ Kammergericht Berlin 13.12.1995, FamRZ 1996, 691, 693.

${ }^{69}$ AG Weilburg 22.6.1994, FamRZ 1995, 242; untribunal ingles negó la restitución por peligro de un daño para el hijo porque la madre padecía de depressiones que se hubieran agravados (Re G (Abduction:Psychological Harm)
[1995] 1 FLR 64, reportado por Young, p. 224.

Revista da Faculdade de Direito da UFRGS, v. 20, Outubro/2001 dres. Lo que es más fácil, viviendo cerca el uno del otro. Al otro lado me parece que hay que considerar también los intereses de la madre de regresar al país de orígen después de que su matrimonio falló

La decisión de la Corte Superior de Connectitut en los Estados Unidos me parece muy remarcable, ya que tomó una decisión en contra de la madre nacional de los Estados Uni$\operatorname{dos}^{70}:$ El tribunal dijo:

"El deseo de la madre de vivir en los Estados Unidos lejos del esposo, es la caus de esta tragedia. Ella escogió el enamorarse, casarse y tener hijos en España. Ahora tiene que enfrentarse a las consecuencias de esta decisión. La corte no puede dar su consentimiento de que una persona sustrae así a sus hijos del país de la residencia de ellos."

En estos casos, la decisión tiene que tomar en cuenta todos estos diferentes aspectos: la edad del menor y su integración en el ambiente de la residencia habitual, el carácter de la relación del menor con el otro padre etc. Para la decisión sobre la restitución del menor, todos estos aspectos formalmente no tienen ninguna importancia.

Según la estructura del convenio la decisión de la restitución no afectará la cuestión de fondo de derecho de custodia. Pero hay que tomar en cuenta, que esta separación total de las dos deciciones significa que el estado de refugio niega toda competencia propia y da la prioridad al estado de la residencia habitual anterior para la cuestión de fondo. En la práctica esta distribución de competencia sólo funciona, si los tribunales encargados de dictar la restitución, tienen la confianza de que en el estado al cual se efectuará la restitución, las decisones se tomarán de una manera imparcia en cuanto a las preferencias nacionales y según

Esto significa que los intereses de madre de no seguir viviendo en el estado de la antigua residencia habitual, no se pueden tomar en cuenta en si mismo según la estructura del convenio. Estos intereses tienen que ser apreciadas en el procedimiento que decide sobre el derecho de custodia o en un procedimiento que permite a la madre de cambiar la residencia habitual sin el consentimiento del padre. Estos procedimientos tienen que llevarse a cabo en el estado de la antigua residencia habitual del menor.

\section{Conclusiones}

Concluyendo se puede constatar. Para que el convenio logre su objetivo, es necesario que la sustracción no tenga efecto positivo para el sustractor. Para ésto, es esencial que la restitución se efectue lo más rápido posible y que no se pueden presentar causas contra la restitución que fueron producidas por la misma sustracción. La cooperación y la ayuda que prestan las autoridades centrales son de enorme imporancia para que los trámites de la restitución se puedan llevar a cabo en un plazo corto. La otra condición esencial consiste en que el tribunal, que decide sobre la restitución, limita su decisión estrictamente a este asunto. Tiene que abstenerse de tomar una decisión sobre el reparto de la custodia. Todas las deliberaciones en cuanto a qué padre la custodia debería ser atribuida tienen que ser excluidas del procedimiento de la restitución. La elitución tiene que ser limitada a la restauración de la situación anterior de la sustracción. Si esta limitación se respeta, son muy pocos los casos en los que la restitución puede ser negada.

${ }^{70}$ No. FA91-0392232S, 1991 Conn. Super. Ct. LEXIS 2215 (Sept. 27, 1991) citado por Silberman, 26. ${ }^{11}$ Silbermann, p. 34; Jayme, IPRax 1995, p. 118 
Mediante la restitución el tribunal entrega toda competencia de nuevo a los tribunales en el estado de la residencia habitual del menor antes de la sustracción. Esta entrega de competencia y esta autolimitación sólo se realizan, si el tribunal, que decide sobre la restitución, tiene la confianza de que la decisión de fondo so- bre la custodia se dicte con imparcialidad en cuanto a las nacionalidades y si los criterios para la decisión son parecidos en los dos estados. Por ésto la cooperación, que el mecanismo del convenio exige, sólo puede funcionar si las concepiones en cuanto al derecho de custodia son parecidas en los países contractantes.

\title{
Entre o "positivismo" "catolicismo": \\ As dimensões do espaço jurídico no Rio Grande do Sul
}

\author{
Fabiano Engelmann \\ Bacharel em Direito UFRGS \\ Mestre em Ciência Política UFRGS \\ Doutorando em Ciência Política UFRGS
}

\section{7} apresenta parte dos resultado corpo docente da Faculdade de Direito de Porto Alegre/UFRGS concernentes a condicionantes sociais de sua formação intelectual e as conseqüências desta formação na estruturação do espaço jurídico sul-riograndense. ${ }^{1} \mathrm{O}$ universo empírico do objeto centrou-se nos docentes que atuaram entre as décadas de 40 e 70 e que podem ser identificados com uma geração que teve ampla participação na definição do universo intelectual no estado.

A definição de um espaço ${ }^{2}$ jurídico no Rio Grande do Sul pode ser entendida em duas dimensões. Na primeira, ocorre a edição de leis que normatizam as profissões jurídicas na década de 30 inserindo-se no processo de corporativização presente no projeto políticoinstitucional do Estado Novo. Esta dimensão comporta paralelamente o crescimento do capital associativo entre os bacharéis originando as associações profissionais (tais como a $\mathrm{OAB}$ / RS) paços de celebração social e gestão do capital de relações sociais entre os profissionais do direito.

Numa segunda dimensão, pode-se acentuar o aumento da produção intelectual na área jurídica objetivada na edição de obras de doutrina e no aparecimento de um grupo de bacharéis sul-rio-grandenses que se associa a uma tradição do "pensamento jurídico gaúcho".

${ }^{1}$ A íntegra da investigação referida pode ser encontrada na dissertação de Mestrado intitulada "A Formação da Elite Jurídica no Rio Grande do Sul" que foi objeto da arguição dos professores Hélgio Trindade, Loiva Otero Felix e Enno D. Liedeke em março de 2001, tendo sido desenvolvida sob a orientação do Prof. Odaci L. Coradini. Os resultados apresentados foram selecionados a partir do segundo capítulo da mesma.

${ }^{2}$ As referências conceituais utilizadas na presente investigação estão ligadas principalmente ao aporte teórico desenvolvido na bibliografia francesa contemporânea acerca da sociologia de elites políticas e culturais, particularmente as pesquisas realizadas por Pierre Bourdieu, Monique de Saint Martin, Yves Dezalay e Cristophe Charle. A explicitação das referências teóricas e metodológicas, bem como, da problemática envolvendo sua aplicação ao caso específico, podem ser encontradas em Engelmann(1999). 